\title{
Daytime space cooling with phase change material ceiling panels discharged using rooftop photovoltaic/thermal panels and night-time ventilation
}

Bourdakis, Eleftherios; Pean, Thibault Quentin; Gennari, Luca; Olesen, Bjarne W.

Published in:

Science and Technology for the Built Environment

Link to article, DOI:

$10.1080 / 23744731.2016 .1181511$

Publication date:

2016

Document Version

Peer reviewed version

Link back to DTU Orbit

Citation (APA):

Bourdakis, E., Pean, T. Q., Gennari, L., \& Olesen, B. W. (2016). Daytime space cooling with phase change material ceiling panels discharged using rooftop photovoltaic/thermal panels and night-time ventilation. Science and Technology for the Built Environment, 22(7), 902-910. https://doi.org/10.1080/23744731.2016.1181511

\section{General rights}

Copyright and moral rights for the publications made accessible in the public portal are retained by the authors and/or other copyright owners and it is a condition of accessing publications that users recognise and abide by the legal requirements associated with these rights.

- Users may download and print one copy of any publication from the public portal for the purpose of private study or research.

- You may not further distribute the material or use it for any profit-making activity or commercial gain

- You may freely distribute the URL identifying the publication in the public portal 


\title{
Daytime space cooling with Phase Change Material (PCM) ceiling panels discharged using rooftop PV/T panels and night-time ventilation
}

\author{
Eleftherios Bourdakis ${ }^{1}$, Thibault Péan ${ }^{1}$, Luca Gennari ${ }^{1}$, Bjarne W. Olesen ${ }^{1}$ \\ ${ }^{1}$ International Centre of Indoor Environment and Energy, Technical University of Denmark, Denmark
}

\begin{abstract}
The possibility of using PhotoVoltaic/Thermal (PV/T) panels for producing cold water through the process of nighttime radiative cooling was examined experimentally. The cold water was used to discharge Phase Change Material (PCM) in ceiling panels in a climatic chamber. Both night-time radiative cooling and night-time ventilation were used as the discharging method in five experiments, simulating summer conditions. The operative temperature remained within the range of Category III of standard DS/EN 15251 for $50 \%$ to $99 \%$ of the occupancy period. The percentage of electrical energy usage covered from the PV/Ts varied from 56\% to 122\%. The PCM ceiling panels were thus capable of providing an acceptable thermal environment and the PV/T panels were able to provide most of the required electricity and cold water needed for cooling.
\end{abstract}

Keywords: Phase change material, Night-time radiative cooling, PhotoVoltaic/Thermal panels, High temperature cooling, Night-time ventilation

\section{Introduction}

The European Parliament (EP) has used ambitious and demanding legislation to stop the continuous increase in energy demand and reduce $\mathrm{CO}_{2}$ emission by EU Member States (EP 2009; EP 2010). In the EU Directive for the Energy Performance of Building (EPBD) it is stipulated that by the 1st of January 2019 all new public buildings must be "nearly Zero Energy Buildings" (nZEB), and that by the 1 st of January 2020 all new buildings should be nZEB (EP 2010). These directives must be followed by all Member States. Two preconditions have to be met in order for the spread of nZEB to be realized. Firstly, the energy usage of buildings has to be reduced drastically and secondly buildings have to be equipped with some means of producing their own energy, such as photovoltaic panels to cover their electrical energy demand, either on an individual building or district scale.

Thermally Active Building Systems (TABS) could contribute to the reduction of the energy required for heating, cooling and ventilation systems. Their high thermal mass results in the distribution of cooling over a longer period of time which leads to lower peaks of cooling/heating demand (Babiak et al. 2013). By reducing the size of the suspended ceiling required for ventilation, since a lower air volume is required, the height of the building can be reduced which results in reduction of building's materials (Babiak et al. 2013). In addition, when using high temperature cooling and low temperature heating systems where the medium temperature needed for cooling/heating is closer to the room temperature, it increases the energy efficiency of heat pumps and ground source heat exchangers (Babiak et al. 2013; Zhao et al. 2013). The ventilation noise level and the risk of draught are reduced and they provide a more uniform thermal environment compared to mixing ventilation systems (Olesen 1997; Olesen 2008). 
Although TABS seem to be a promising solution for new construction, they are not always applicable to renovation, since it is technically difficult to include a new $150 \mathrm{~mm}$ concrete ceiling in an existing building. This drawback could be solved by installing radiant systems which include Phase Change Material (PCM), since they have the thickness of a lightweight construction but their effective thermal mass is comparable to that of a heavyweight construction (Koschenz \& Lehmann 2004). PCMs can be either organic or inorganic substances that absorb latent heat when they melt and release it when they solidify. The biggest benefits of implementing PCM in the structure or ceiling panels are the reduction of peak cooling demand, the shift of part of the cooling demand to nighttime (when lower electricity tariffs occur in several countries), the reduced fluctuation of the room temperature, the reduction in the size of the HVAC system that is required and the more rapid charge and discharge rates that can be achieved compared to conventional concrete (Cabeza et al. 2007; BASF 2010; Krasimirov Pavlov 2014).

Radiative heat transfer to the night sky is a method which could be used as the cooling source for discharging PCMs inside the building. Solar panels release heat in the form of longwave radiation towards the night sky $\left(-40^{\circ} \mathrm{C} /-40^{\circ} \mathrm{F}\right)$. The benefits of nighttime radiative cooling are the low energy usage (since only a water circulation pump is required); the higher utilization factor of the solar panels (since they are exploited also during nighttime); that cold water production and cooling demand are in phase, since clear skies occur more often during the summer period, and that they can be coupled with thermal storage systems such as TABS and PCM (Meir et al. 2002; Eicker \& Dalibard 2011; Hosseinzadeh \& Taherian 2012).

The use of photovoltaic/thermal panels (PV/T) panels for nighttime radiative cooling together with PCM for space cooling has been reported by (Eicker \& Dalibard 2011; Lin et al. 2014; Fiorentini et al. 2015) and in the first of these the PCM was part of the radiant cooling system. The purpose of the present experiment was to demonstrate that the coupling of PV/T panels with a radiant ceiling cooling system containing PCM can contribute to the realization of nZEB. The system was evaluated in terms of the resulting indoor thermal conditions, the cooling output and electricity production of the PV/T panels and the heat stored in the PCM panels.

\section{Method}

A climate chamber at the International Centre for Indoor Environment and Energy (ICIEE) at the Technical University of Denmark (DTU) was used. The chamber was located inside a larger building, so it was not exposed to the ambient weather conditions. The floor area was $22.7 \mathrm{~m}^{2}(5.4 \mathrm{~m} \mathrm{X} 4.2 \mathrm{~m})$ while the height was $3 \mathrm{~m}$. The walls and the roof of the chamber consisted of two steel sheets separated by $100 \mathrm{~mm}$ of mineral wool.

At $2.5 \mathrm{~m}$ above the floor, the PCM panels were installed as a suspended ceiling. The plenum that was formed between the suspended ceiling and the chamber's roof was used to supply fresh air inside the room through the gaps between the PCM panels. 24 PCM panels were installed, and the dimensions of each panel were $1.25 \mathrm{~m} \mathrm{X} 0.625 \mathrm{~m} \mathrm{X} 0.025 \mathrm{~m}$, containing $6 \mathrm{~kg}$ of PCM each. The PCM that was used is microencapsulated paraffin with a melting point of $23^{\circ} \mathrm{C}$. The curves of the thermal capacity versus the temperature for the melting and solidifying processes are shown in Figure 1. For discharging the PCM, Alu-PEX pipes were embedded inside the panels to circulate cold water. The external diameter of the pipes was $8 \mathrm{~mm}$, the thickness $1 \mathrm{~mm}$ and the pipe spacing $100 \mathrm{~mm}$. As it can be seen in Figure 2, eight panels had surface temperature sensors attached both on the upper and the lower surface, while in three panels a heat flux sensor was attached. 


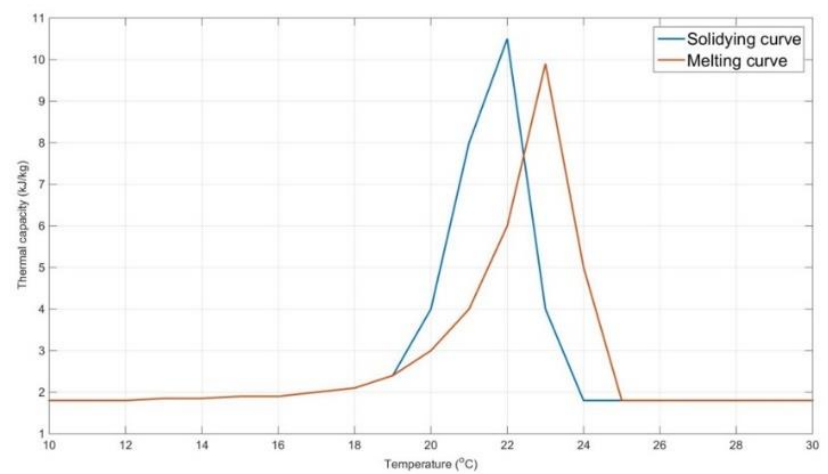

Figure 1: Thermal capacity versus temperature

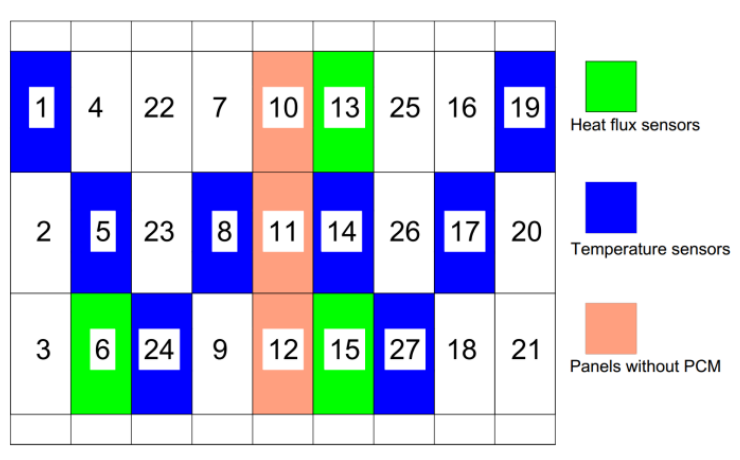

Figure 2: Sensors' location on PCM panels

The chamber interior was arranged to simulate a two-person office, as shown in Figure 3. Heated manikins were used to simulate two occupants and office equipment was simulated using heated dummies. They were activated only during typical office hours, namely from 9:00 to 17:00 and only on weekdays. The total power from the two occupants, the office equipment and the four ceiling lamps was $540 \mathrm{~W}\left(23.8 \mathrm{~W} / \mathrm{m}^{2}\right)$. The office equipment consisted of two laptops with an additional screen each and two desktop lamps. Behind each "occupant", there was a stand with an operative temperature sensor $0.6 \mathrm{~m}$ above the floor, and four air temperature sensors at heights of $0.1 \mathrm{~m}, 0.6 \mathrm{~m}, 1.1 \mathrm{~m}$ and $1.7 \mathrm{~m}$. Those heights correspond to the ankle, abdomen and neck of a seated person and the neck of a standing person, respectively, as recommended by Standard ISO 7726 (2001).

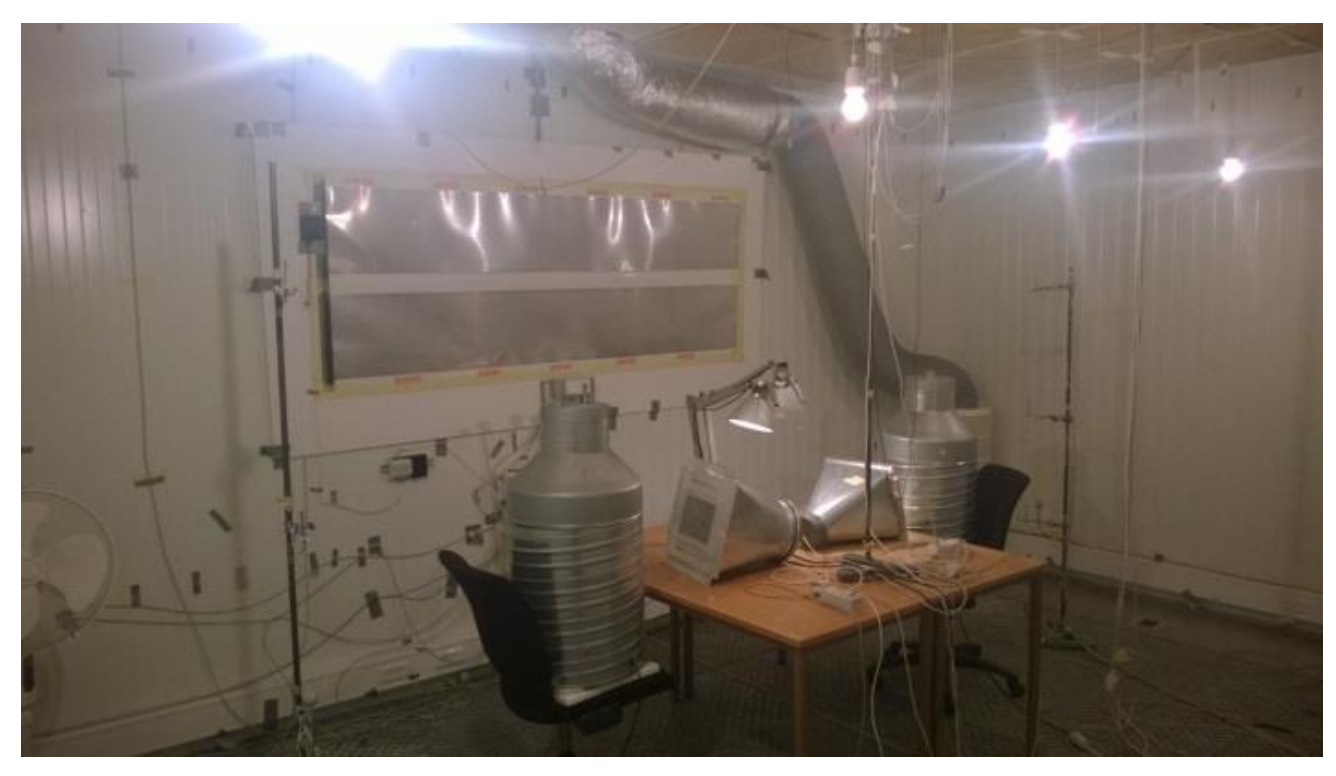

Figure 3: Chamber's interior

The chamber was not directly exposed to sunlight, but an electrical heating wall panel was used to simulate the solar load of a window located on the south wall of the office, as may be seen in the background of Figure 3. For defining the daily solar heat gains profile, a simulation in TRNSYS was run using the International Weather for Energy Calculations (IWEC) file for Copenhagen. From this simulation, the average value of longwave radiation passing a window located on the south wall per minute was defined for the cooling period (namely from $1^{\text {st }}$ of May until $30^{\text {th }}$ of October). Since the control system for the electrical heating panel could only be set in multiples of $25 \mathrm{~W}$, the daily schedule was adjusted as shown in Figure 4. 


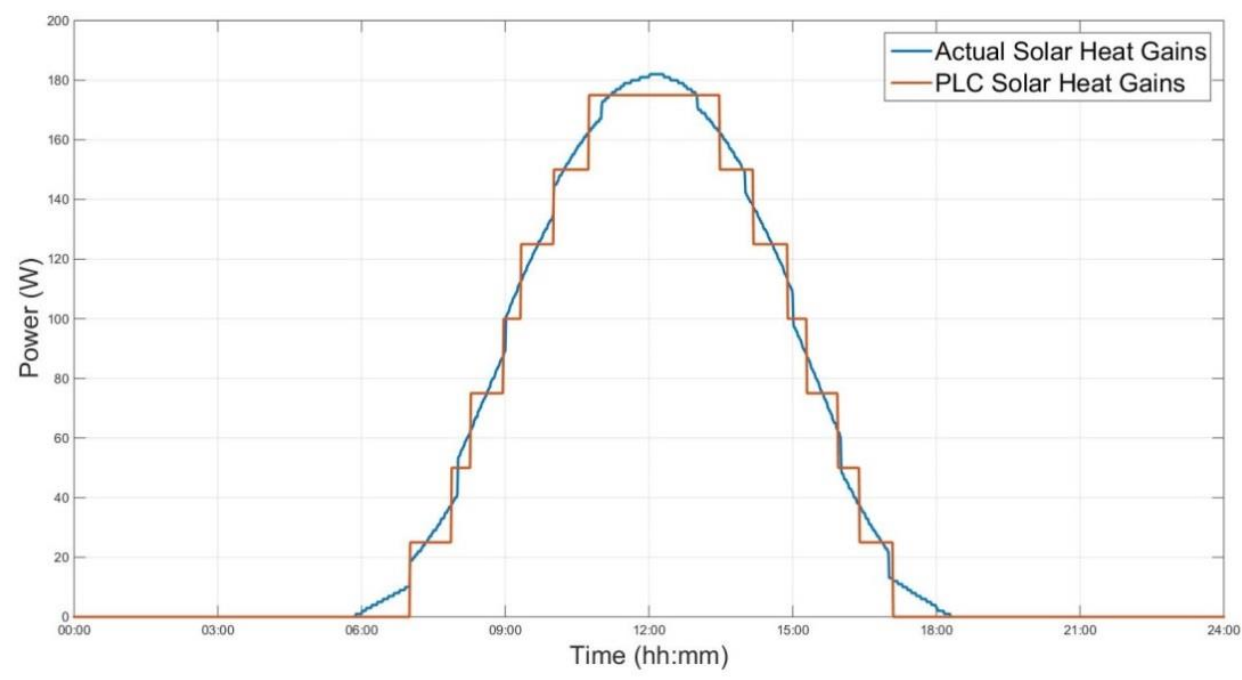

Figure 4: Daily solar heat gains profile

The air supply temperature was varying from $18^{\circ} \mathrm{C}$ to $20^{\circ} \mathrm{C}$, while the ventilation flow rate was set to $30 \mathrm{l} / \mathrm{s}$. This air flow rate judged adequate for providing fresh air and removing latent heat gains and pollutants to an office the size of the climate chamber, based on Annex B.1.2 of the standard DS/EN 15251 (DS/EN 2007b). The ventilation was operated from 9:00 to 17:00. As stated above, the air was supplied from a plenum above the PCM panels, while the exhaust diffuser was located behind one of the "occupants", as may be seen in Figure 2. The ventilation was also operated to discharge the PCM at night in three experimental cases, as set out in Table 1.

On the roof of the building where the chamber was located, three polycrystalline PV/T panels were installed. The surface of each panel was $1.3 \mathrm{~m}^{2}$ and they were facing south with a tilt angle of $45^{\circ}$. The water flow rate in the solar loop was $94 \mathrm{~L} / \mathrm{h}$. As shown in Figure 5, the PV/T panels were connected through a heat exchanger with two storage tanks. The volume of each tank was $255 \mathrm{~L}$. One tank was used to store hot water (HWT) while in the second one, cold water (CWT) was stored. A plate heat exchanger was installed between the panels and the tanks due to different water pressure in the solar loop and the tanks. This restricted the quantity of glycol as much as possible, which was required as antifreeze in the solar loop. The direction of the water after the heat exchanger toward the hot water or cold water storage tanks was determined automatically based on the two following conditions:

- If $T_{P V / T}-T_{H W T}>1 \mathrm{~K}$ then water directed towards HWT

- If $T_{C W T}-T_{P V / T}>1 \mathrm{~K}$ then water directed towards CWT

where

$T_{P V / T}$ is the water temperature exiting the PV/T panels

$T_{H W T}$ is the temperature in the middle of the HWT

$T_{C W T}$ is the temperature in the middle of the CWT

The location of the three sensors measuring $T_{P V / T}$, the $T_{H W T}$ and the $T_{C W T}$ are shown in Figure 5. If neither of the two conditions was met, then the pump between the heat exchanger and the tanks was switched off. The CWT had two internal spiral heat exchangers. As it is shown in Figure 5, the upper one was connected to the plate heat exchanger, while the lower one was connected to the main chiller 
of the laboratory facilities. The main chiller was used as an auxiliary system for providing cold water whenever the production from nighttime radiative cooling was not sufficient. The water supply temperature of the main chiller was $7^{\circ} \mathrm{C}$. The water from the bottom of the CWT was circulated to the PCM panels and from there it was returned to the top of the CWT. The water flow rate was $210 \mathrm{~kg} / \mathrm{h}$ and the circulation of the water was started at 5:00 and continued until 9:00, provided that the following conditions were met:

- The average lower surface temperature of the PCM panels was above $21^{\circ} \mathrm{C}$

- The operative temperature of the room was above $21^{\circ} \mathrm{C}$

- The temperature of the water in the middle of the CWT was below $20^{\circ} \mathrm{C}$

During the occupant period, the water circulation to the PCM panels was activated automatically if the temperature at the middle of the CWT was below $20^{\circ} \mathrm{C}$ and the operative temperature of the room was above $25.5^{\circ} \mathrm{C}$.

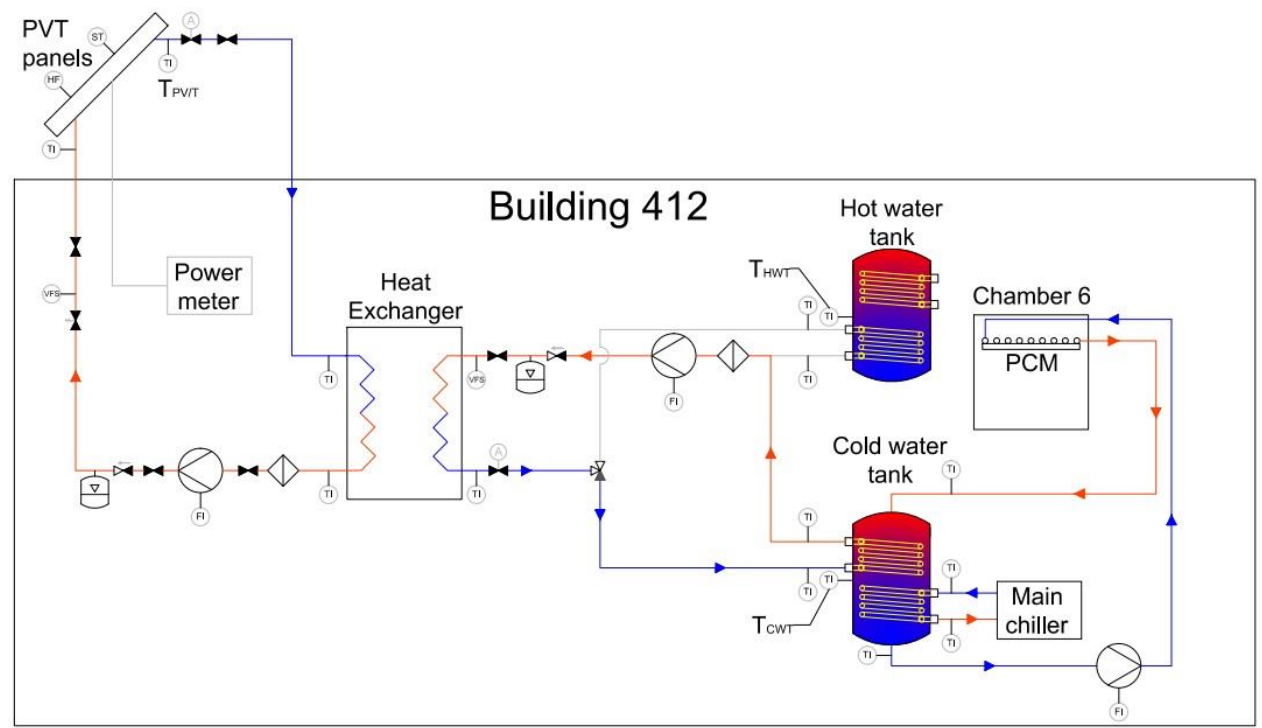

Figure 5: Schematic drawing of the hydraulic system

In Table 1 the configurations that were examined are tabulated. The duration for each of them was five weekdays and the experiment was performed from July 2015 to September 2015. In addition to night-time radiative cooling, night-time ventilation and the combination of the two were examined as methods for discharging the PCM. In the second and the third configuration the air mixing was improved by turning on two floor fans. In the last configuration the embedded water cooling system was deactivated and only night-time ventilation was used for discharging the PCM panels.

Table 1. Cases Examined

\begin{tabular}{cccc}
\hline Case number & $\begin{array}{c}\text { Nighttime } \\
\text { ventilation }\end{array}$ & Improved air mixing & $\begin{array}{c}\text { Activation of } \\
\text { embedded water } \\
\text { system }\end{array}$ \\
\hline 1 & No & No & Yes \\
2 & No & Yes & Yes \\
3 & $301 / \mathrm{s}$ at $18^{\circ} \mathrm{C}-20^{\circ} \mathrm{C}$ & Yes & Yes \\
4 & $301 / \mathrm{s}$ at $18^{\circ} \mathrm{C}-20^{\circ} \mathrm{C}$ & No & Yes \\
5 & $30 \mathrm{l} / \mathrm{s}$ at $18^{\circ} \mathrm{C}-20^{\circ} \mathrm{C}$ & No & No \\
\hline
\end{tabular}




\section{Results}

In Figure 6 the operative temperature for all six configurations is presented. The grey shaded areas are the occupancy periods, while the three pairs of horizontal dashed lines show the lower and upper limits of the Categories I, II and III of Standard DS/EN 15251 (DS/EN 2007b).

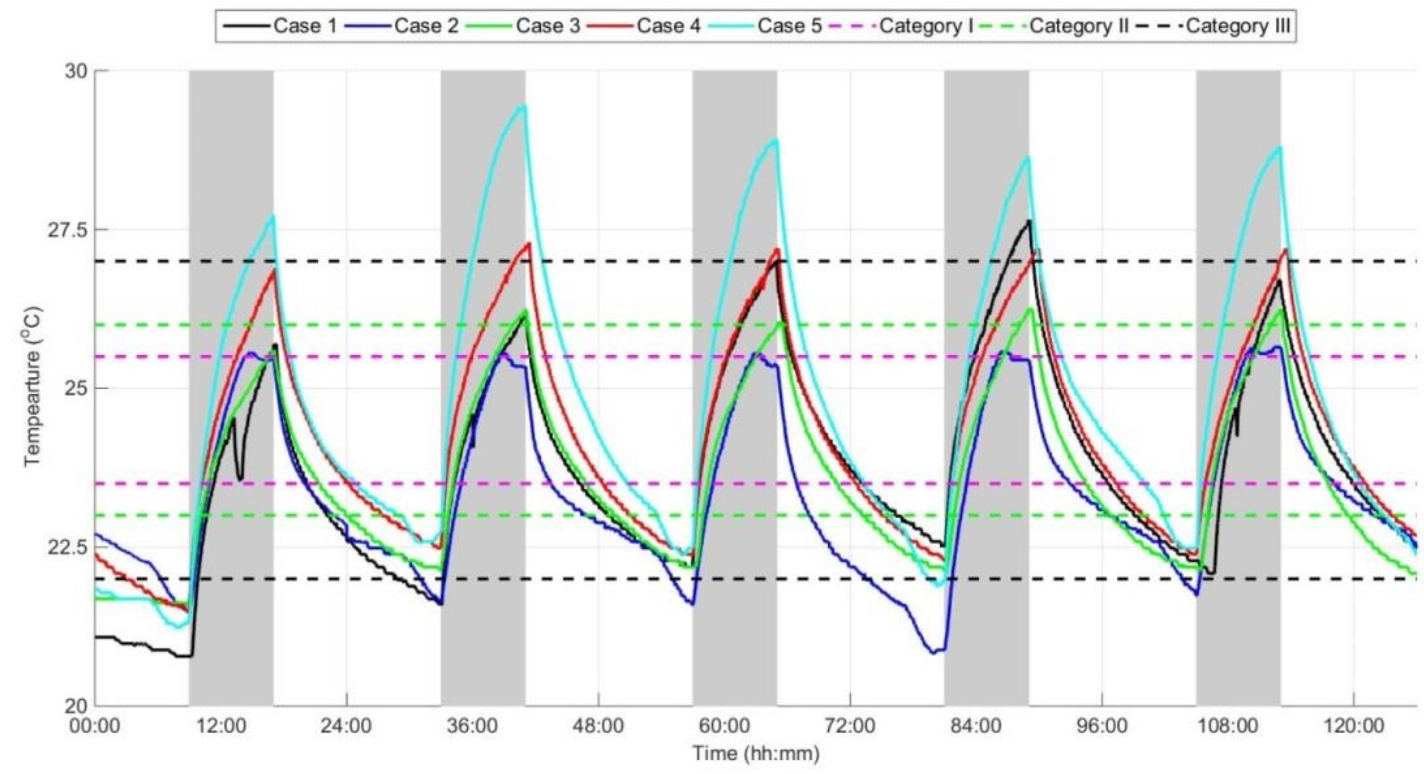

Figure 6: Operative temperature

The percentages of the occupancy period where the operative temperature was within the limits of each category of standard DS/EN 15251 (DS/EN 2007b) are presented in Table 2. The temperature should be within the ranges $23.5-25.5^{\circ} \mathrm{C}, 23-26^{\circ} \mathrm{C}$ and $22-27^{\circ} \mathrm{C}$ for Category I, II and III, respectively.

Table 2: Percentages of Occupancy Period in Categories of Standard EN 15251

\begin{tabular}{cccc}
\hline Case Number & Category I, \% & Category II, \% & Category III, \% \\
\hline \hline 1 & 45 & 63 & 92 \\
2 & 59 & 84 & 95 \\
3 & 57 & 81 & 99 \\
4 & 37 & 58 & 95 \\
5 & 19 & 29 & 50 \\
\hline
\end{tabular}

It can be observed that the configuration which achieved the highest percentage of time within the range of Category III was the third configuration, in which the operative temperature was within the limits for $99 \%$ of the occupancy period. The configuration in which the worst thermal conditions were provided was the fifth case, in which the embedded water cooling system was deactivated and the PCM was discharged only by nighttime ventilation.

In Figure 7 the total energy output of the PV/Ts and the PCM for each configuration is shown (in each case, the energy accumulated over five days). It may be seen that the amount of energy stored in 
the CWT is significantly higher than the energy stored in the HWT. For the energy stored in the CWT, only the operation of the PV/Ts was taken into consideration, while the impact of the main chiller was not included in the calculations. It can be seen that in Configurations 1 to 4 the energy removed by the PCM was 38 to $59 \%$ lower than the energy stored in the CWT. The last configuration was not taken into consideration since the water stored in the CWT tank was not utilized for discharging the PCM.

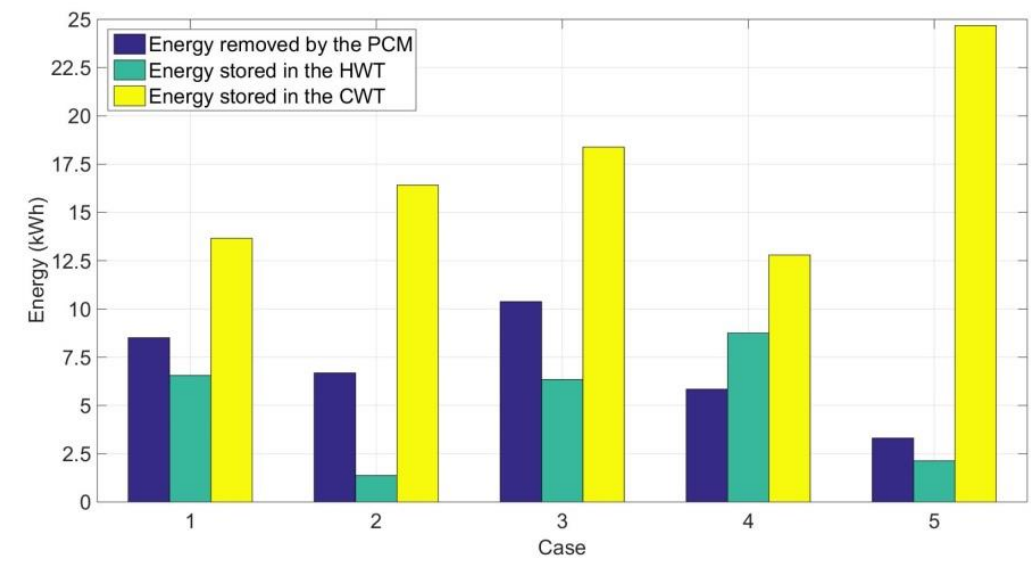

Figure 7: Energy output of the PV/Ts and the PCM

The average power per $\mathrm{m}^{2}$ of the PV/T panels in terms of producing electricity, hot water and cold water is presented in Table 3.

Table 3: Average Power of the PV/T Panels

\begin{tabular}{cccc}
\hline Case Number & $\begin{array}{c}\text { Average electrical } \\
\text { power, W/m }\end{array}$ & $\begin{array}{c}\text { Average hot water } \\
\text { production power, } \\
\mathrm{W} / \mathrm{m}^{2}\end{array}$ & $\begin{array}{c}\text { Average cold water } \\
\text { production power, } \\
\mathrm{W} / \mathrm{m}^{2}\end{array}$ \\
\hline \hline 1 & 51 & 35 & 70.8 \\
2 & 51.9 & 27 & 56.3 \\
3 & 63.2 & 72.1 & 76.5 \\
4 & 31.9 & 39.7 & 67.1 \\
5 & 28 & 72.2 & 82.1 \\
\hline
\end{tabular}

In Figure 8 a comparison between the electrical energy production and electrical energy usage is presented. The latter is tabulated separately for the office equipment, the pumps, the ventilation and the main chiller. The energy usage of the office equipment was always $9.1 \mathrm{kWh}$. The pumps bar shows the energy usage of all three pumps shown in Figure 5. The solar loop pump was operated continuously, while the operation of the other two pumps differed between configurations. The total energy usage of the three pumps varied from $1.3 \mathrm{kWh}$ (Config.5) to $1.6 \mathrm{kWh}$ (Configs.1 and 4). The lower energy usage in the fifth case was expected since the PCM pump was deactivated. The ventilation bar includes the energy usage of the fan and the cooling coil. The energy usage of the ventilation system varied from $1.2 \mathrm{kWh}$ in Configs. 1 and 2 , to $3.6 \mathrm{kWh}$ in the others. The higher energy usage in the last three cases was because the ventilation was also operated during the night. Since the specific fan power (SFP) was not known, an SFP of $1000 \mathrm{~W} /\left(\mathrm{m}^{3} / \mathrm{s}\right.$ ) was assumed, which corresponds to Category SFP 3 of the standard DS/EN 13779 (DS/EN 2007a). In order to calculate the 
energy usage of the cooling coil and the chiller it was assumed that an air-to-water heat pump was used. The specifications of a heat pump available on the market were used, based on which a seasonal COP of 4.5 was calculated. With this COP, the electricity usage of the chiller in Configs. 1 to 4 varied from $0.4 \mathrm{kWh}$ in Config.2, to $10 \mathrm{kWh}$ in Config.3, while in the fifth configuration it was deactivated. The electrical energy production from the PV/Ts varied from $9.4 \mathrm{kWh}$ (Config.4) to $20.3 \mathrm{kWh}$ (Config.3). This considerable difference between the different configurations can be explained by the different weather conditions to which the panels were exposed at during the experiment. The percentage of electricity usage covered from PV/Ts varied from $56 \%$ in case 4 , to $122 \%$ in case 2 which was the only case in which the electrical energy production from the PV/Ts covered the electrical energy demand of the chamber.

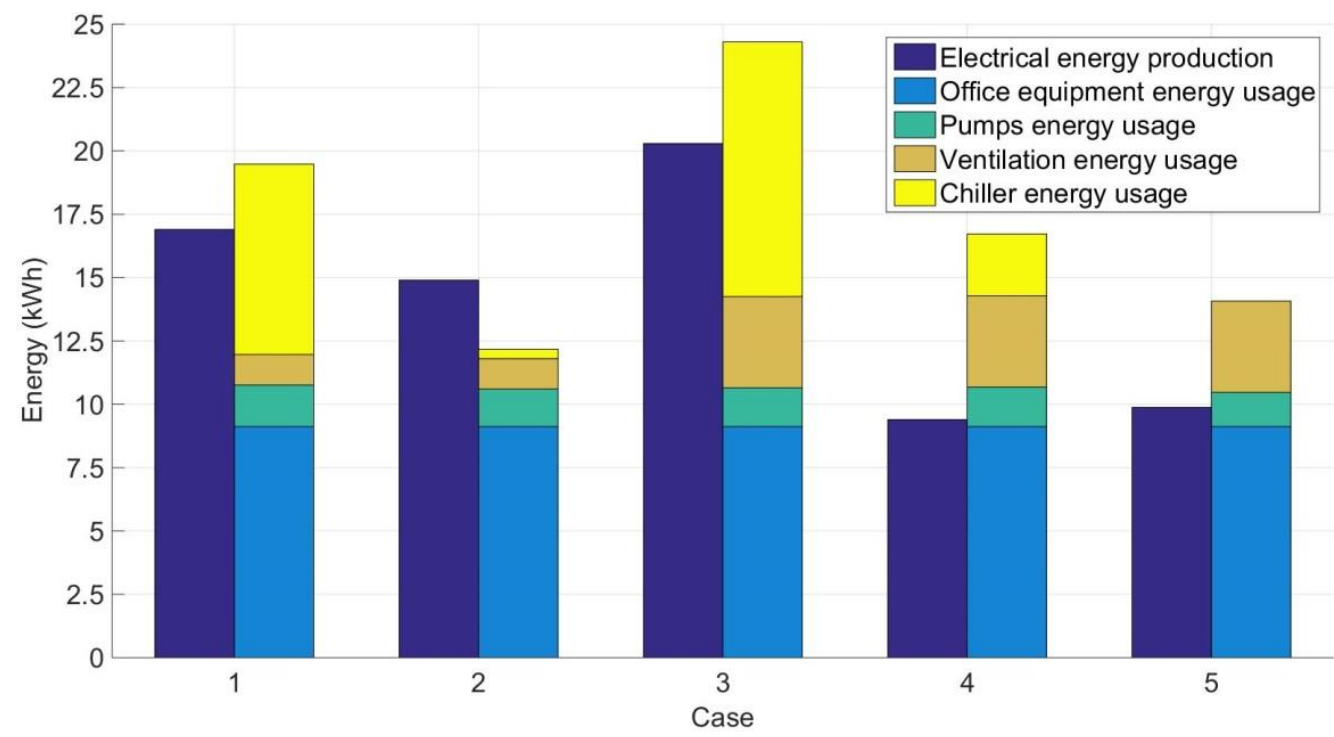

Figure 8: Energy production and usage comparison

\section{Discussion}

Analyzing the performance of each configuration in terms of Category III, it may be seen that improving the air mixing in the second configuration resulted in a slight improvement in the percentage of time within the Category III range by $3 \%$, while adding night-time ventilation resulted in a further improvement of $4 \%$ in the third configuration. When air mixing was no longer increased artificially, the percentage dropped back to $95 \%$. By comparing the second and the fourth configuration, it may be seen that although they were within the Category III range for the same percentage of time, in Configuration 2 the percentage of time within the Category I and II ranges was significantly higher than in Configuration 4 , in which these percentages were less than that of the first configuration. Improving the air mixing thus had a bigger impact in improving thermal conditions than implementing night-time ventilation. In Configuration 5, the air flow rate or air temperature proved insufficient for discharging the PCM which resulted in overheating during the occupied period.

Since the chamber was not exposed to the weather conditions, the ambient conditions for the chamber and the PV/Ts were not always the same. The ambient air temperature and the air temperature inside the building housing the chamber during Configuration 1 are shown in Figure 9. 
The ambient air temperature was measured at a weather station installed next to the PV/T panels, while the building air temperature was measured just outside the chamber. The small fluctuation in the building's air temperature ensured that the performance of the PCM was affected only by the configuration employed and not by external factors such as the ambient weather conditions.

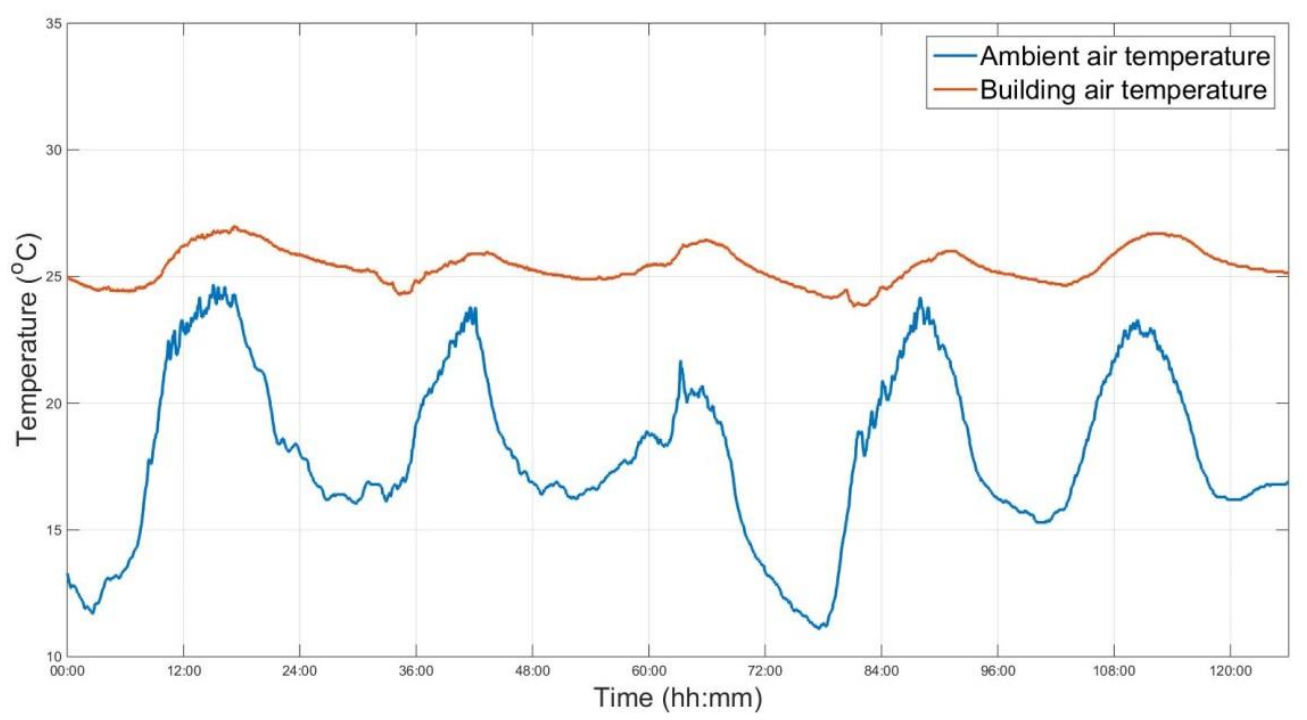

Figure 9: Ambient and Building air temperature (10-14 August 2015)

All the parameters that were related to the $\mathrm{PV} / \mathrm{T}$ panels, e.g. water flow rate, tilt angle and orientation, were kept constant through all five different configurations. Therefore, the fluctuations observed in the results presented in Figure 7 and Table 3 were caused by changes in the ambient weather conditions which are shown in Table 4 . An accurate performance of the panels thus cannot be estimated without a detailed weather prediction.

Table 4: Ambient Weather Conditions During the Experiments

\begin{tabular}{cccccccc}
\hline $\begin{array}{c}\text { Case } \\
\text { Number }\end{array}$ & $\begin{array}{c}\text { Min. outside } \\
\text { Air } \\
\text { temperature, } \\
{ }^{\circ} \mathrm{C}\end{array}$ & $\begin{array}{c}\text { Max. outside } \\
\text { air } \\
\text { temperature, } \\
{ }^{\circ} \mathrm{C}\end{array}$ & $\begin{array}{c}\text { Aver. outside } \\
\text { Air } \\
\text { temperature, } \\
{ }^{\circ} \mathrm{C}\end{array}$ & $\begin{array}{c}\text { Solar } \\
\text { radiation } \\
\text { on the } \\
\text { panels, } \\
\mathrm{kWh} / \mathrm{m}^{2}\end{array}$ & $\begin{array}{c}\text { Total rain } \\
\text { precipitation, } \\
\mathrm{mm}\end{array}$ & $\begin{array}{c}\text { Max. } \\
\text { wind } \\
\text { speed, } \\
\mathrm{m} / \mathrm{s}\end{array}$ & $\begin{array}{c}\text { Aver. } \\
\text { wind } \\
\text { speed, } \\
\mathrm{m} / \mathrm{s}\end{array}$ \\
\hline \hline 1 & 11.1 & 24.7 & 18.2 & 1656 & 4.8 & 5.4 & 1.1 \\
2 & 7.2 & 19.2 & 13.5 & 1276 & 0.4 & 4.9 & 1.1 \\
3 & 13.5 & 25.6 & 19.0 & 1908 & 0.0 & 4.9 & 1.7 \\
4 & 10.1 & 21.8 & 15.6 & 898 & 14.8 & 6.7 & 1.5 \\
5 & 9.1 & 20.4 & 14.8 & 1130 & 24.8 & 7.2 & 1.8 \\
\hline
\end{tabular}

The experiment was mainly focused on examining the performance of the night-time radiative cooling principle, so the hot water stored in the HWT was not utilized. During a sunny day the temperature in the HWT increased considerably. Since the hot water was not used, the only temperature drop in the HWT was caused by heat losses. Therefore, the following day the pump placed after the heat exchanger would hardly be activated since Condition (1) (as stated in the Method 
paragraph) would not be fulfilled, even if the weather conditions were capable of producing hot water. This can be seen in Figure 10, which shows the temperature in the middle of the HWT and the solar radiation measured during the first experiment. This resulted in an underestimation of the performance of the PV/Ts in terms of domestic hot water production.

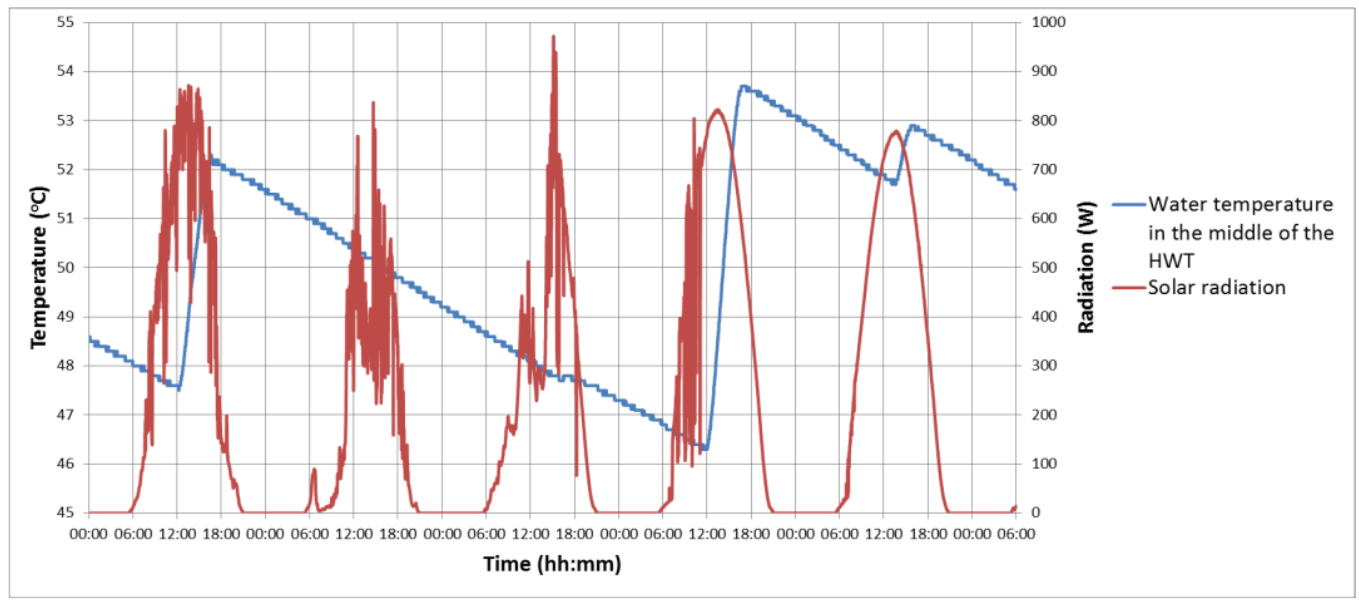

Figure 10: Correlation between solar radiation and HWT temperature (10-14 August 2015)

As it is shown in Figure 7, in order to discharge the PCM panels completely, more energy was required than the actual energy that is stored in the panels. This is due to the low thermal conductivity of the PCM used in the specific panels. Connecting directly the PV/Ts with the PCM panels would reduce the heat losses, but since cold water was also circulated during daytime, the storage tank could not be avoided.

Péan et al. (2015) measured the cooling power of PV/T panels for two weeks and an average value of $89.6 \mathrm{~W} / \mathrm{m}^{2}$ was measured. Only the result of the fifth configuration was comparable to the results obtained by Péan et al., while it was significantly lower in all of the other configurations. For the two experiments the same panels were used. The fluctuation observed in the values of the two experiments were attributed to the different values of the water flow rate $(94 \mathrm{~L} / \mathrm{h}$ in the present experiment while $120 \mathrm{~L} / \mathrm{h}$ in Pèan's et al. (2015) experiment) and the variation of the weather conditions during the two experiments.

Although in most of the configurations the PV/Ts did not provide all of the electrical energy required, the production of hot and cold water from the PV/Ts would reduce the operating time of chillers or heaters. If a water-to-water heat pump or a ground source heat exchanger was used instead of an air-to-water heat pump a higher COP would be achieved and the energy usage of the chiller would be reduced.

\section{Conclusions}

1) The PCM ceiling panels were capable of providing an acceptable thermal environment in the office room when the embedded cooling pipes were in use. 2) The air flow rate proved insufficient when only night-time ventilation was used as discharging method. 3) PV/T panels can be an efficient solution for producing electrical energy, domestic hot water and cold water for space cooling, 
contributing to the spread of near Zero Energy Buildings. 4) Although the PV/T panels performed satisfactorily, their performance cannot be accurately predicted due to variation in the weather conditions to which they were exposed.

\section{Acknowledgements}

The experiment was funded by the International Centre for Indoor Environment and Energy (ICIEE), the Development Program (ELFORSK), project no. 346-037, "Sustainable plus-energy houses - Part 2: SDE2014" and the Nordic Built Project "Low Temperature Heating And High Temperature Cooling In Refurbishment And New Construction Of Buildings". The authors thank Nico Henrik Ziersen and Ioannis Ipliktsiadis for their contribution to building the hydraulic and electrical installations used in the experiment, respectively.

\section{Reference}

Babiak, J., Olesen, B.W. \& Dušan Petráš, 2013. Low Temperature Heating and High Temperature Cooling,

BASF, 2010. Micronal PCM - Intelligent Temperature Management for Buildings. Available at: http://www.micronal.de/portal/load/fid774774/Catalogue Micronal PCM.pdf.

Cabeza, L.F. et al., 2007. Use of microencapsulated PCM in concrete walls for energy savings. Energy and Buildings, 39(2), pp.113-119.

DS/EN, 2007a. 13779: Ventilation for non-residential buildings. Performance requirements for ventilation and room-conditioning systems. , (2).

DS/EN, 2007b. DS/EN 15251:2007 Indoor environment input parameters for design and assessment of energy performance of buildings adressing indoor air quality, thermal environment, lighting and acoustics.

DS/EN ISO, 2001. ISO 7726: Ergonomics of the thermal environment - Instruments for measuring physical quantities.

Eicker, U. \& Dalibard, A., 2011. Photovoltaic-thermal collectors for night radiative cooling of buildings. Solar Energy, 85(7), pp.1322-1335. Available at:

http://dx.doi.org/10.1016/j.solener.2011.03.015.

EP, 2009. Directive 2009/28/EC of the European Parliament and of the Council of 23 April 2009 on the promotion of the use of energy from renewable sources and amending and subsequently repealing Directives 2001/77/EC and 2003/30/EC. Official Journal of the European Union, 140(16), pp.16-62.

EP, 2010. Directive 2010/31/EU of the European Parliament and of the Council of 19 May 2010 on the energy performance of buildings (recast). Official Journal of the European Union, pp.13-35.

Fiorentini, M., Cooper, P. \& Ma, Z., 2015. Development and optimization of an innovative HVAC system with integrated PVT and PCM thermal storage for a net-zero energy retrofitted house. Energy and Buildings, 94, pp.21-32. Available at:

http://www.sciencedirect.com/science/article/pii/S0378778815001139.

Hosseinzadeh, E. \& Taherian, H., 2012. An Experimental and Analytical Study of a Radiative Cooling 
System with Unglazed Flat Plate Collectors. International Journal of Green Energy, 9(October), pp.766-779. Available at: http://www.scopus.com/inward/record.url?eid=2-s2.084870328243\&partnerID=tZOtx3y1.

Koschenz, M. \& Lehmann, B., 2004. Development of a thermally activated ceiling panel with PCM for application in lightweight and retrofitted buildings. Energy and Buildings, 36(6), pp.567-578. Available at: http://www.sciencedirect.com/science/article/pii/S0378778804000702 [Accessed October 8, 2015].

Krasimirov Pavlov, G., 2014. Building Thermal Energy Storage. , (April), p.313.

Lin, W. et al., 2014. Development and evaluation of a ceiling ventilation system enhanced by solar photovoltaic thermal collectors and phase change materials. Energy Conversion and Management, 88, pp.218-230. Available at:

http://www.sciencedirect.com/science/article/pii/S0196890414007432.

Meir, M.G., Rekstad, J.B. \& Løvvik, O.M., 2002. A study of a polymer-based radiative cooling system. Solar Energy, 73(6), pp.403-417.

Olesen, B., 1997. Possibilities and Limitations of Radiant Floor Cooling. ASHRAE TransactionsAmerican ..., pp.42-48.

Olesen, B., 2008. Radiant floor cooling systems. Ashrae Journal, 50(9), p.16-+.

Zhao, K., Liu, X.-H. \& Jiang, Y., 2013. Application of radiant floor cooling in a large open space building with high-intensity solar radiation. Energy and Buildings, 66, pp.246-257. 